\title{
Pharmacological inactivation of the PI3K p110 prevents breast tumour progression by targeting cancer cells and macrophages
}

Evangelia Goulielmaki ${ }^{1}$, Miriam Bermudez-Brito ${ }^{1}$, Margarita Andreou', Niki Tzenaki ${ }^{1}$, Maria Tzardi ${ }^{2}$, Eelco de Bree ${ }^{3}$, Eleftheria Tsentelierou ${ }^{4}$, Antonis Makrigiannakis ${ }^{4}$ and Evangelia A. Papakonstanti ${ }^{1}$

\begin{abstract}
Patient selection for PI3K-targeted solid cancer treatment was based on the PIK3CA/PTEN mutational status. However, it is increasingly clear that this is not a good predictor of the response of breast cancer cells to the anti-proliferative effect of PI3K inhibitors, indicating that isoform(s) other than p110a may modulate cancer cells sensitivity to PI3K inhibition. Surprisingly, we found that although no mutations in the p110 $\delta$ subunit have been detected thus far in breast cancer, the expression of p110 becomes gradually elevated during human breast cancer progression from grade I to grade III. Moreover, pharmacological inactivation of p110 $\mathrm{in}$ mice abrogated the formation of tumours and the recruitment of macrophages to tumour sites and strongly affected the survival, proliferation and apoptosis of grafted tumour cells. Pharmacological inactivation of p1108 in mice with defective macrophages or in mice with normal macrophages but grafted with p1108-lacking tumours suppressed only partly tumour growth, indicating a requisite role of p1108 in both macrophages and cancer cells in tumour progression. Adoptive transfer of $\delta^{\mathrm{D} 910 \mathrm{~A} / \mathrm{D} 910 \mathrm{~A}}$ macrophages into mice with defected macrophages suppressed tumour growth, eliminated the recruitment of macrophages to tumour sites and prevented metastasis compared with mice that received WT macrophages further establishing that inactivation of $\mathrm{p} 110 \delta$ in macrophage prevents tumour progression. Our work provides the first in vivo evidence for a critical role of p1108 in cancer cells and macrophages during solid tumour growth and may pave the way for the use of p1108 inhibitors in breast cancer treatment.
\end{abstract}

\section{Introduction}

The class IA subset of phosphoinositide-3 kinases (PI3Ks) are heterodimers made up of a regulatory subunit and a $110 \mathrm{kDa}$ catalytic subunit $(\mathrm{p} 110 \alpha, \mathrm{p} 110 \beta$ or $\mathrm{p} 110 \delta)^{1-3}$. The $\mathrm{p} 110 \alpha$ isoform is a well-known oncoprotein since gain-of-function mutations in PIK3CA gene are present in a wide variety of human solid tumours ${ }^{4-7}$. The p110 $\beta$ isoform has been implicated in platelet biology, thrombosis ${ }^{8}$ and in certain cancers, especially in tumour

\footnotetext{
Correspondence: Evangelia A. Papakonstanti (epapak@uoc.gr)

${ }^{1}$ Department of Biochemistry, School of Medicine, University of Crete,

Heraklion, Greece

${ }^{2}$ Department of Pathology, University Hospital, School of Medicine, University of Crete, Heraklion, Greece

Full list of author information is available at the end of the article.

Edited by M. Piacentini.
}

cells lacking phosphatase and tensin homolog on chromosome 10 (PTEN) ${ }^{9-13}$. The gene encoding $\mathrm{p} 110 \delta$ is rarely mutated in cancers ${ }^{6,14-21}$, and because of the preferential expression of $\mathrm{p} 110 \delta$ in leukocytes this isoform has been mostly considered as a target in immunity and inflammation $^{22-24}$. PI3K p110 $\delta$ has been found to play also a seminal role in lymphoid and myeloid malignancies ${ }^{25-29}$ and a potent p110 $\delta$-selective inhibitor, Idelalisib, has been recently approved for the treatment of haematologic malignancies ${ }^{30}$. A promising role of the PI3K p110 has also been suggested in cancers of nonhaematopoietic origin ${ }^{29}$; however, the role of p110 $\delta$ in breast cancer in vivo is poorly explored.

Deregulated PI3K signalling in breast cancer has frequently been attributed to gain-of-function mutations in 
PIK3CA gene, encoding the PI3K p110 $\alpha$ and/or to loss-offunction mutations in the PTEN gene $\mathrm{e}^{6,31-35}$. For this reason, the PIK3CA/PTEN mutational status was originally considered as a predictive molecular parameter of the sensitivity of cancer cells to PI3K inhibitors. However, recent studies have shown that there is no good correlation between the PIK3CA or PTEN mutational status and the response of breast cancer cells to the anti-proliferative effect of PI3K inhibitors ${ }^{36-38}$ indicating that unidentified mechanisms and/or isoform(s) other than $\mathrm{p} 110 \alpha$ modulate the sensitivity of breast cancer cells to PI3K inhibition. An equally unexplained observation is that although PTEN somatic mutations are not very often in human breast cancers ${ }^{39}$, the deregulated PI3K activity in breast cancer cells is not controlled by wild-type (WT) PTEN.

Based on these observations, our work aimed to study a putative role of the PI3K $\mathrm{p} 110 \delta$ in breast tumour progression providing new guidance for a potentially beneficial use of $p 110 \delta$-selective inhibitors alone or in combination with inhibitors of other components of PI3K pathway. We report that pharmacological inactivation of p110 $\delta$ blocks breast tumour growth by targeting cancer cells and macrophages. Our work also shows that the expression of $\mathrm{p} 110 \delta$ is gradually increased during breast cancer progression and this correlates with a gradually decreased activity of PTEN, which overcomes and remains constantly high upon pharmacological inactivation of $\mathrm{p} 110 \delta$. These results strongly provide a rationale for considering the use of p1108-selective inhibitors in breast cancer treatment and for the establishment of p110 expression as a useful prognostic marker for the response of tumours expressing WT PTEN to p110 $\delta$ inhibitors.

\section{Results}

Human breast cancer progression correlates with elevated PI3K p1108 expression levels

Given that no somatic mutations of PIK3CD gene encoding the PI3K $\mathrm{p} 110 \delta$ have been reported in breast cancer ${ }^{6,14-17}$, we sought to explore the $\mathrm{p} 110 \delta$ protein expression during human breast cancer progression by immunohistochemistry in a collection of human breast carcinomas of grade I $(n=20)$, grade II $(n=20)$ and grade III $(n=20)$. p110 $\delta$ was detected as cytoplasmic staining in all carcinomas and in some cases p110 $\delta$ was additionally detected as focal staining and in deposits (Fig. 1a). However, p110 $\delta$ staining positivity, quantified either as the percentage of p110 $\delta$-stained cancer cells (Fig. 1b) or as mean reciprocal intensity of $\mathrm{p} 110 \delta$ staining in cancer cells (Fig. 1c), was much higher in grade II and III carcinomas compared with grade I carcinomas. We also assessed the expression of p110 $\delta$ in macrophages in human breast tumours. Double immunostaining of human breast carcinomas of grade III for $\mathrm{p} 110 \delta$ and CD68 revealed strong p1108 staining in macrophages (CD68+ cells) (Fig. 1d), which had an intensity similar with that measured in cancer cells (Fig. 1e). To confirm that the anti-p110 antibody specifically recognizes the p $110 \delta$ isoform, we tested it on sections from ovarian and cervical human cancers, which are known to express very low levels of $\mathrm{p} 110 \delta$ but high levels of $\mathrm{p} 110 \alpha$ and/or $\mathrm{p} 110 \beta^{40}$. Indeed, the anti-p110 $\delta$ antibody detected very low p110 $\delta$ immunoreactivity in those sections whereas strongly stained $\mathrm{p} 110 \delta$ on breast cancer sections (Figure S1).

The collection of the human breast carcinomas used for the evaluation of p110 $\delta$ levels was consisting of estrogen receptor (ER)- and/or progesterone receptor (PR)- positive, as well as ER-and/or PR-negative tumours whereas all tumours were human epidermal growth factor receptor 2 (HER2) negative. The results were similar in all samples regardless of ER or PR assignment, indicating that the p1108 staining does not correlate with the ER- or PRpositivity.

The above results indicate that the PI3K p1108 might play a functional role in human breast cancer.

\section{Oral administration of the IC87114 p1108-selective inhibitor abrogates breast tumour growth in vivo and prevents the localization of macrophages into tumour sites}

To test the hypothesis that the PI3K p110 $\delta$ has an essential role in tumour growth, we inoculated the MDAMB-231 human breast cancer cell line into Balb/c nude mice to generate mammary tumours. MDA-MB-231 cells express high levels of p110 $\delta$ comparable with those expressed in macrophages (Figure S2 and ref. ${ }^{40}$ ). Intratumoural administration of IC87114, a small molecule inhibitor with selectivity for $\mathrm{p} 110 \delta^{41}$, from day +15 , when the tumour was palpable, significantly reduced tumour volume (Fig. 2a) suggesting that the inhibition of p110 affects the proliferation of cancer cells and/or cells of the tumour microenvironment. However, tumours kept growing in smaller size (Fig. 2a). Surprisingly, when IC87114 was administered per os there was an almost complete lack of tumour growth (Fig. 2b) suggesting that p110 $\delta$ needs to be additionally inactivated possibly in a sub-population of white blood cells, which when recruited to tumour sites counterbalance the effect of the intratumoural administration of IC87114 on tumour growth. The greater efficacy of oral treatment versus intratumoural injection of IC87114 seems not to depend on the timing of first administration. Indeed, similar blockade of tumour growth was achieved whether the inhibitor was administered per os from day +15 (Fig. 2b, upper panel), which was also the time of first intratumoural injection, or starting on the day of tumour cell engraftment, day 0 (Fig. 2b, lower panel).

Balb/c nude mice lack $\mathrm{T}$ cells but produce other subtypes of white blood cells. In recent years, tumour- 


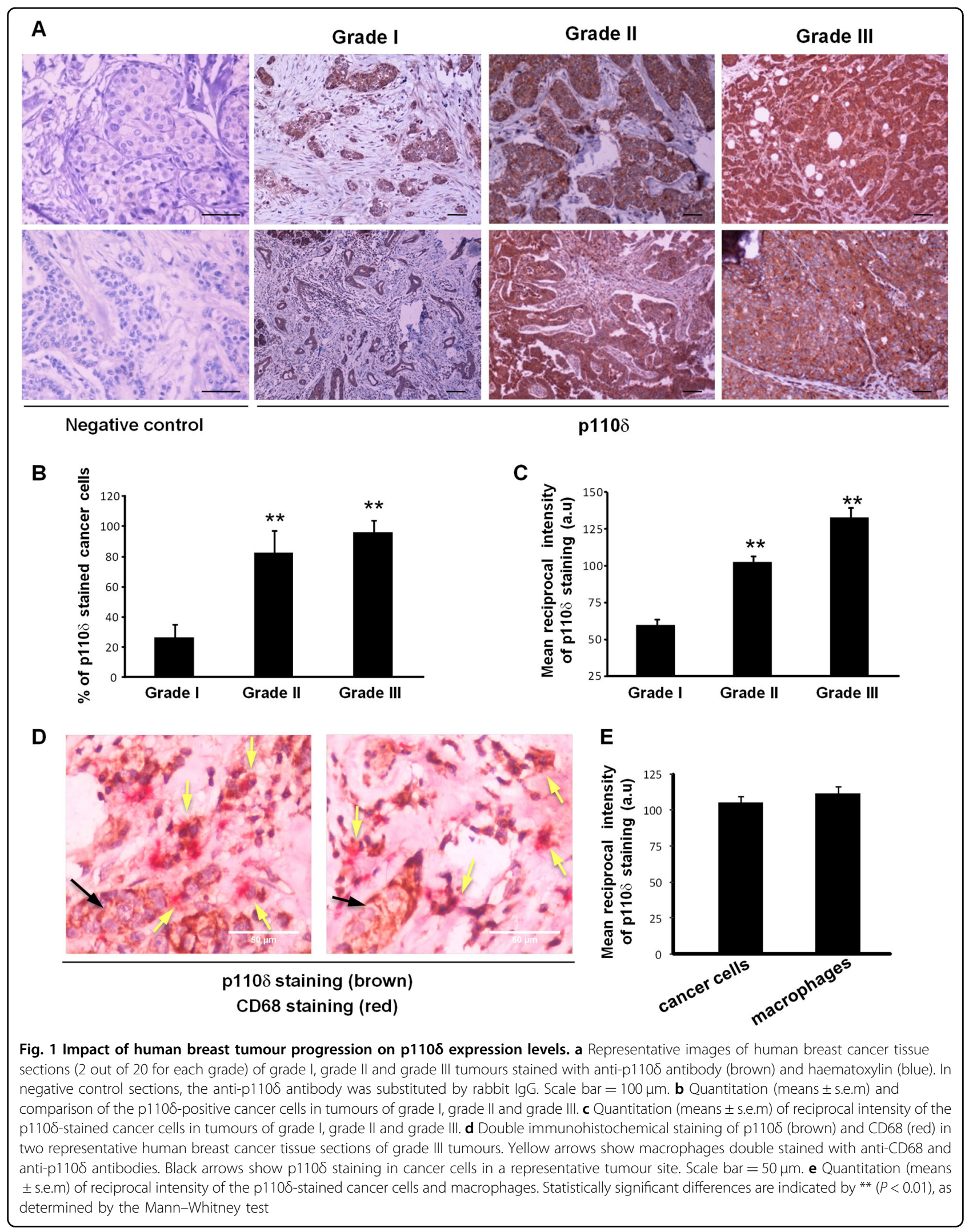




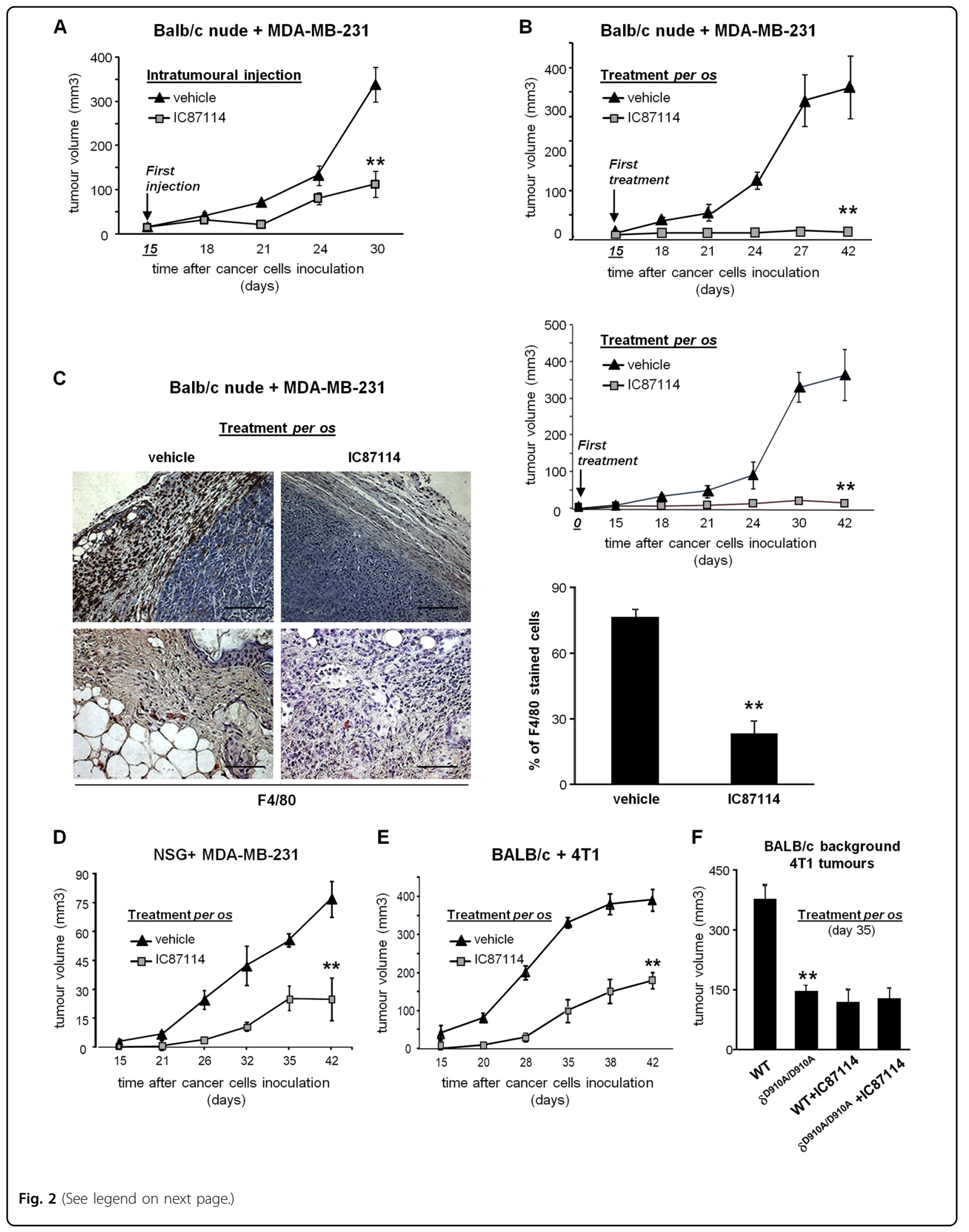




\begin{abstract}
(see figure on previous page)
Fig. 2 Impact of pharmacological inactivation of $\mathrm{p} 110 \delta$ on breast tumour growth and on the recruitment of macrophages to tumour sites. a Growth of primary MDA-MB-231 tumours, inoculated in the breast fat pad of BALB/c nude mice, measured by digital callipers and expressed as tumour volume. Mice were treated intratumourally with vehicle or IC87114 (35 mg/kg). The drug was administered on day +15 and on every other day until day 30. $n=7$ mice/group. $\mathbf{b}$ Growth of primary MDA-MB-231 tumours, inoculated in the breast fat pad of BALB/c nude mice, measured by digital callipers and expressed as tumour volume. Mice were treated once daily per os with vehicle or IC87114 (35 mg/kg) from day +15 (upper panel) or from day 0 (lower panel). $n=9$ mice/group. c Immunohistochemical staining of macrophage-specific antigen F4/80 (brown) and haematoxylin (blue) in two representative sections of tumours excised from BALB/c nude mice that were treated per os with vehicle or IC87114 (35 mg/kg) (left panel). Scale bar $=50 \mu \mathrm{m}$. Comparison of F4/80-positive cells in tumours of IC87114-treated and vehicle-treated mice (right panel). $\mathbf{d}$ Growth of primary MDA-MB-231 tumours, inoculated in the breast fat pad of NOD scid gamma (NSG) mice, measured by digital callipers and expressed as tumour volume. Mice were treated once daily per os with vehicle or IC87114 (35 mg/kg) from day +15. $n=9$ mice/group. e Growth of primary 4T1 tumours, inoculated in the breast fat pad of BALB/c mice, measured by digital callipers and expressed as tumour volume. Mice were treated once daily per os with vehicle or IC $87114(35 \mathrm{mg} / \mathrm{kg})$ from day $+15 . n=9$ mice/group. $\mathbf{f}$ Growth of primary $4 \mathrm{~T} 1$ tumours, inoculated in the breast fat pad of WT or $\delta^{\mathrm{D} 910 \mathrm{~A} / \mathrm{D} 910 \mathrm{~A}}$ mice on BALB/c background, measured by digital callipers and expressed as tumour volume. Mice were treated once daily per os with vehicle or IC87114 (35 mg/kg) from day $+15 . n=10$ mice/group. All graphs represent means \pm s.e.m. Statistically significant differences are indicated by ** $(P<0.01)$, as determined by the Mann-Whitney test
\end{abstract}

associated macrophages (TAMs) have received great attention as key players in supporting tumour progression since they produce factors, which promote breast tumour growth and angiogenesis, suppress the anticancer immune responses and enhance the invasive potential of breast cancer cells ${ }^{42-44}$. To explore this possibility, we tested the impact of oral administration of IC87114 or vehicle on the recruitment of macrophages to tumour sites in MDA-MB-231-bearing Balb/c nude mice. Immunostaining of tumour samples for the macrophagespecific antigen F4/80 revealed that the abundance of macrophages, including those in the tumour stroma and tumour-infiltrating macrophages (Fig. 2c, left panel), was drastically reduced in mice receiving per os IC87114 (Fig. 2c, right panel). These data suggest that under per os treatment conditions, the inhibition of PI3K p110 $\delta$ has a negative impact on the survival and/or recruitment of macrophages to tumour environment, which may additionally account for tumour regression.

To further assess the functional importance of the PI3K p110 in both macrophages and cancer cells, we evaluated the impact of $\mathrm{p} 110 \delta$ inhibition on tumour growth in two specific combinations of host mice and tumour cells: we used tumour cells expressing p $110 \delta$ inoculated into mice with defective macrophages and tumour cells lacking p110 growing up in mice with normal macrophages. In particular, we assessed (a) the growth of MDA-MB-231 tumours, which express p110 $\delta$ in NOD scid gamma (NSG) mice that have defective macrophages and lack T cells (Fig. 2d and Supp Fig. 2) and (b) the growth of the syngeneic 4T1 tumours, which do not express p110 $\delta$ in the Balb/c strain mice, which have normal macrophages and $\mathrm{T}$ cells (Fig. 2e and Supp Fig. 2). Oral administration of IC87114 either in MDA-MB-231 tumour-bearing NSG mice (Fig. 2d) or in 4T1 tumour-bearing Balb/c mice (Fig. 2e) reduced, but did not entirely block, tumour growth in both cases. Abrogation of tumour growth was only observed in per os-treated MDA-MB-231 tumour- bearing Balb/c nude mice, which, although lack T cells, have normal macrophages expressing p110 $\delta$ and $\mathrm{p} 110 \delta$ expressing tumours (Fig. 2b).

We also assessed the growth of 4T1 tumours in $\delta^{\mathrm{D} 910 \mathrm{~A} /}$ D910A mice in which the endogenous $110 \delta$ kinase has been genetically inactivated ${ }^{45}$. In parallel, we investigated the impact of IC87114 on tumour growth in WT and $\delta^{\mathrm{D} 910 \mathrm{~A} / \mathrm{D} 910 \mathrm{~A}}$ mice. Genetic inactivation of $\mathrm{p} 110 \delta$ in host animals suppressed 4T1 tumour growth to a similar extend as pharmacological inactivation of p110 $\delta$ in WT mice. Importantly, IC87114 did not further affect tumour growth in $\delta^{\mathrm{D} 910 \mathrm{~A} / \mathrm{D} 910 \mathrm{~A}}$ mice (Fig. 2f) confirming that IC87114 is an 'on target' p110 $\delta$ inhibitor in vivo.

The above data suggest that the PI3K p110 $\delta$ needs to be inactivated in both cancer cells and macrophages for an efficient blockade of tumour growth.

\section{Inactivation of the PI3K p110 in macrophages is sufficient to confer tumour growth regression and to prevent metastasis}

To further confirm the functional impact of the PI3K p $110 \delta$ inactivation in macrophages on tumour progression, we carried out adoptive macrophage transfer experiments in MDA-MB-231 tumour-bearing NSG mice. When $\delta^{\mathrm{D} 910 \mathrm{~A} / \mathrm{D} 910 \mathrm{~A}}$ macrophages, which express genetically inactivated $\mathrm{p} 110 \delta^{45}$ were transferred into NSG mice, the tumour burden was significantly reduced compared with that observed in mice that received WT macrophages (Fig. 3a). In addition, immunostaining of tumour samples with the macrophage-specific antigen F4/ 80 (Fig. 3b, upper panel) showed that the abundance of macrophages into tumour sites was significantly reduced in mice receiving $\delta^{\mathrm{D} 910 \mathrm{~A} / \mathrm{D} 910 \mathrm{~A}}$ macrophages compared with mice receiving WT macrophages (Fig. 3b, lower panel).

We then assessed the role of the PI3K p110 in macrophages in controlling cancer cells metastasis by determining the tumour cell blood burden and the expression 


\section{NSG mice + MDA-MB-231+ macrophage transfer}

A

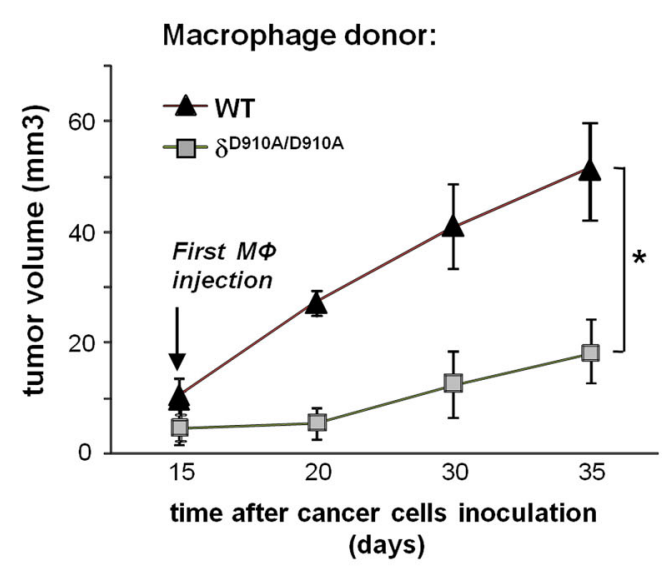

C

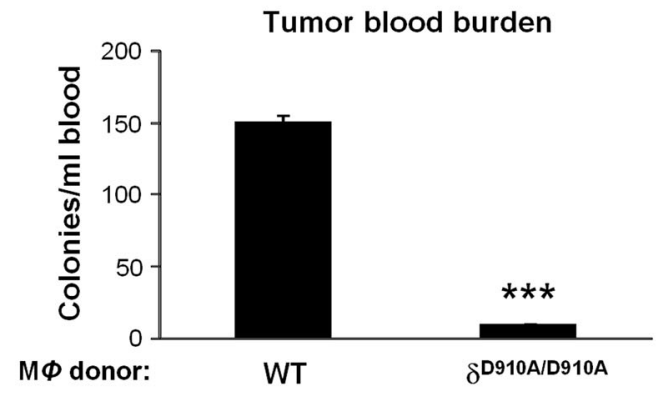

B

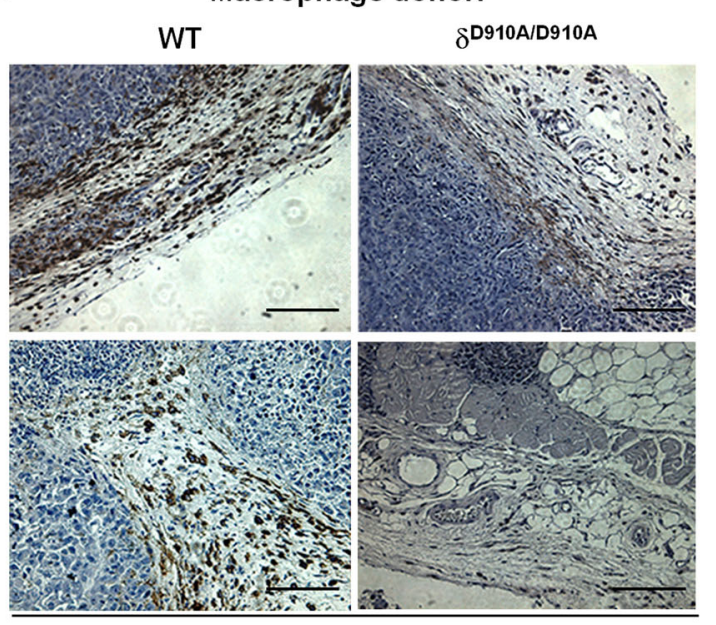

$F 4 / 80$

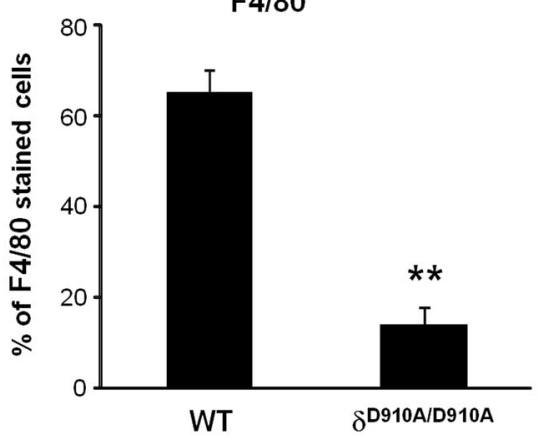

D

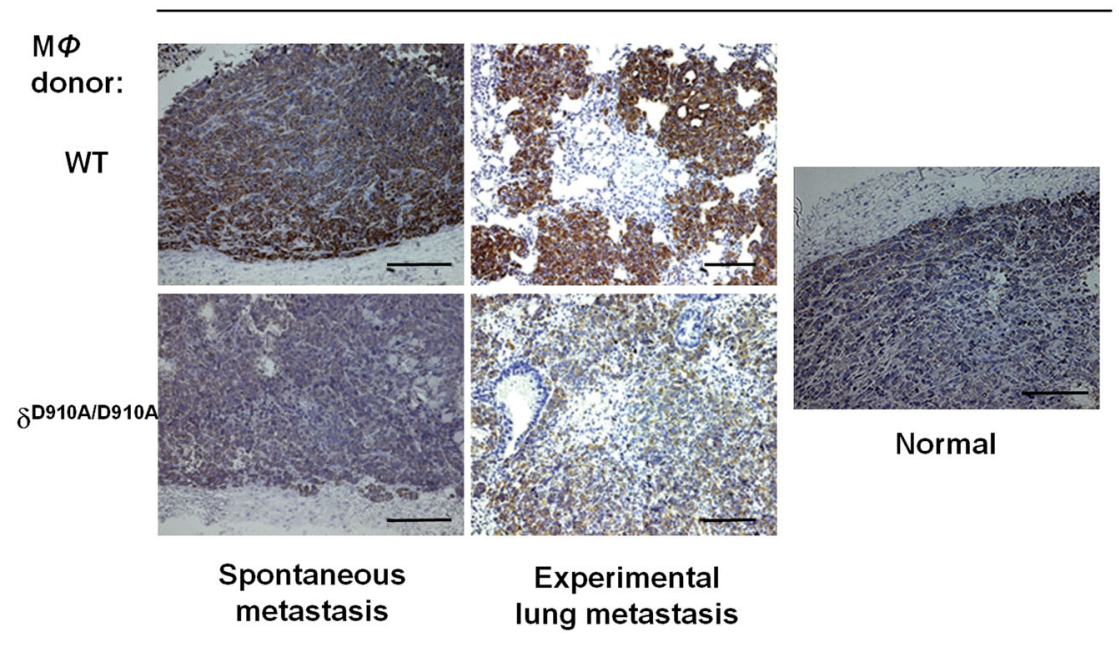

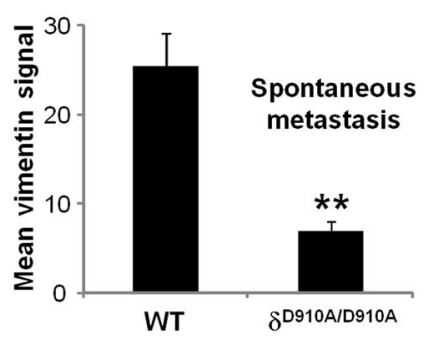

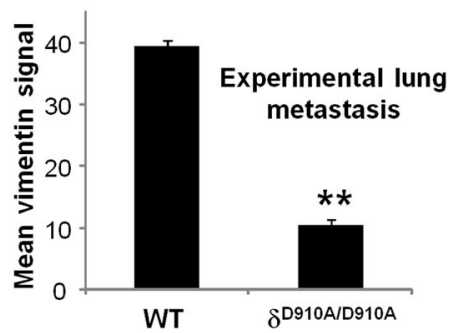

Fig. 3 (See legend on next page.) 
(see figure on previous page)

Fig. 3 Inactivation of the PI3K p1108 in macrophages is sufficient to suppress tumour growth and metastasis. a Impact of adoptive transfer of $\delta^{\mathrm{D} 910 \mathrm{~A} / \mathrm{D} 910 \mathrm{~A}}$ macrophages into NSG mice on MDA-MB-231 primary tumour growth. $n=8$ mice/group, ${ }^{*}(P<0.05)$ as determined by the Mann-Whitney test. $\mathbf{b}$ Impact of adoptive transfer of WT or $\delta^{\mathrm{D} 910 \mathrm{~A} / \mathrm{D} 910 \mathrm{~A}}$ macrophages into NSG mice on the recruitment of macrophages to tumour sites. Representative images of immunohistochemical staining with anti-F4/80 antibody (brown) and haematoxylin (blue) in two representative sections of tumours from NSG mice received WT or $\delta^{D 910 A D 910 A}$ macrophages (upper panel). Scale bar $=50 \mu \mathrm{m}$. Comparison of F4/80-positive cells in tumours from NSG mice received WT or $\delta^{\mathrm{D} 910 \mathrm{~A} / \mathrm{D} 910 \mathrm{~A}}$ macrophages (lower panel). $\mathbf{c}$ Intravasation efficiency of cancer cells as determined by tumour cells blood burden at the end point of spontaneous metastasis in NSG mice, which received WT or $\delta^{\text {D910A D910A macrophages }(M \Phi) . n=16,{ }^{* * *}(P<}$ 0.001), as determined by the Mann-Whitney test. $\mathbf{d}$ Invasion of cancer cells as determined by immunohistological staining of vimentin (brown) in the lungs of NSG mice, which received WT or $\delta^{\mathrm{D} 910 \mathrm{~A} / \mathrm{D} 910 \mathrm{~A}}$ macrophages during the spontaneous and experimental lung metastasis assay. Normal lung is also shown. Scale bar $=50 \mu \mathrm{m}$. Graphs represent quantification of the vimentin signal in tissue samples of the respective lungs (right panels). All graphs represent means \pm s.e.m. Statistically significant differences are indicated by ** $(P<0.01)$, as determined by the Mann-Whitney test

of vimentin in the lungs. The tumour cell number in the blood collected from the right atrium of the heart before filtration by the lungs, is a direct evaluation of intravasation and therefore of efficiency of metastasis ${ }^{46}$, whereas elevated expression of vimentin is correlated with lung invasion of cancer cells ${ }^{47,48}$. To evaluate the impact of p110 inactivation in macrophages on early and late steps of metastasis, we used MDA-MB-231 tumour-bearing NSG mice for spontaneous metastasis and NSG mice in which experimental lung metastasis assay ${ }^{46}$ was performed followed by the adoptive transfer of macrophages. Under conditions of adoptive transfer of $\delta^{\mathrm{D} 910 \mathrm{~A} / \mathrm{D} 910 \mathrm{~A}}$ macrophages in MDA-MB-231 tumour-bearing NSG mice, the tumour blood burden was significantly reduced (Fig. 3c) indicating that the spontaneous intravasation and therefore metastasis is prevented when $\mathrm{p} 110 \delta$ in macrophages is inactive. Similarly, transfer of $\delta^{\mathrm{D} 910 \mathrm{~A} / \mathrm{D} 910 \mathrm{~A}}$ macrophages either into NSG mice bearing MDA-MB231 tumours or into mice with experimental lung metastasis led to reduced expression of vimentin in the lungs (Fig. 3d) reflecting decreased invasion of cancer cells.

Together, these data indicate that targeting of PI3K p110 in macrophages is sufficient to prevent the localization of macrophages into tumour sites and consequently to suppress tumour growth and metastasis.

\section{Pharmacological inactivation of the PI3K p110 affects the survival, proliferation and apoptosis of tumour cells}

To assess the direct effect on tumour cells, we investigated whether the treatment of BALB/c nude mice with the p110 $\delta$ inhibitor per os affects the survival, proliferation rate and apoptosis of tumour cells and can therefore account for the reduced tumour growth. The phosphorylated Akt (Fig. 4a), as well as the 5-bromo-2'deoxyuridine (BrdU)-positive cells (Fig. 4b) were significantly reduced in tumour specimens from mice treated with IC87114 compared with vehicle, indicating reduced survival and proliferative rate of tumours upon p110 $\delta$ inhibition. The number of terminal deoxynucleotidyl transferase-mediated dUTP nick end labelling (TUNEL)- positive cells was also significantly increased in IC87114treated mice (Fig. 4c), suggesting induced apoptosis in tumour cells.

Taken together, the above results show that pharmacological inhibition of the PI3K p110 $\delta$ prevents tumour progression by directly affecting both cancer cells and macrophages.

\section{Elevated $\mathrm{p} 110 \delta$ expression levels correlate with reduced PTEN activity in late tumour stages}

The finding described above showing that the expression of the PI3K p1108 becomes elevated during human breast cancer progression (Fig. 1) indicates that high p110 expression may associate with enhanced survival of cancer cells. In an attempt to identify the mechanism that could explain how high p110 expression in advanced tumour stages associates with the survival of cancer cells, we assessed a potential correlation between p110 $\delta$ expression levels and PTEN activity during tumour growth, based on previous findings of ours showing that the two correlate in breast cancer cell lines ${ }^{40,49}$. Balb/c nude mice receiving vehicle alone, were left to develop MDA-MB-231 tumours for different time periods (Fig. 5a, black bars) in an attempt to mimic breast tumour progression from early to late stages; the excised tumours were first examined by histology (Fig. 5b). Cancer cells characterized by large nucleus, nucleoli and undergoing mitosis and hair follicles with infiltrating cancer cells in otherwise healthy epidermis were detected in tissue specimens from mice that carried the tumours for up to 28 days (Fig. 5b). Healthy epidermal and stromal cells were also found in these tumours (Fig. 5b). Cancer cells under mitosis, muscle infiltration of the tumour and large necrotic areas, which reflect the development of invasive cancer and tumour aggressiveness, were present in the excised tissues when tumours were left to grow for up to 49 days (Fig. 5b). Allowing further tumour growth for up to 60 days showed characteristics indicating that tumours outgrew their blood supply such as necrotic areas in the tumour and necrotic epidermis. Mitotic cancer cells were also still observed (Fig. 5b). 


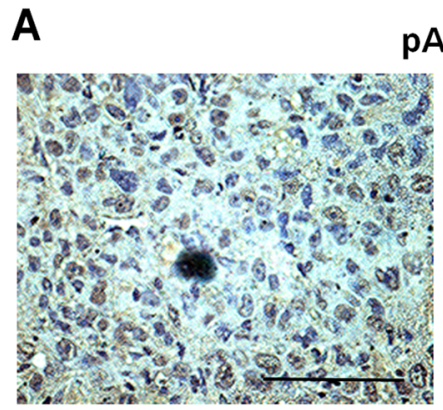

vehicle

\section{B}

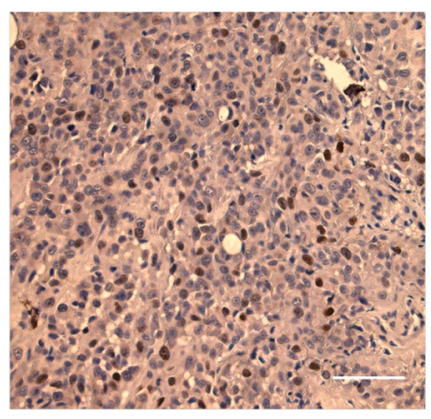

vehicle

C

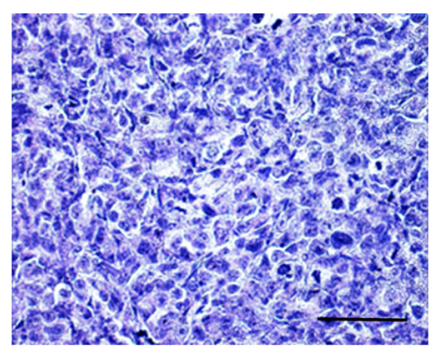

vehicle
pAkt

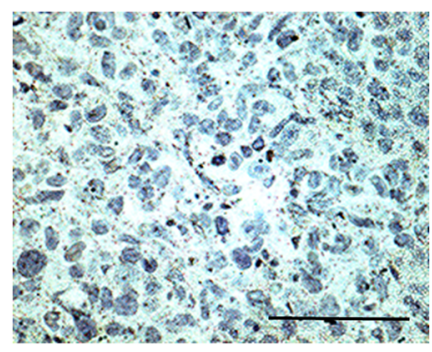

IC87114

BrdU

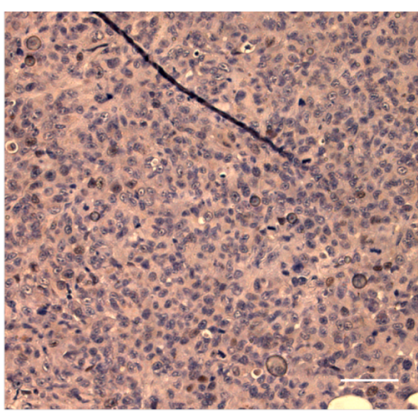

IC87114

TUNEL

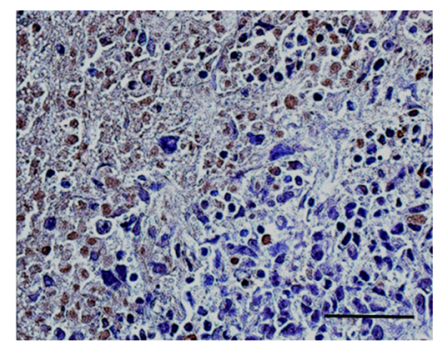

IC87114
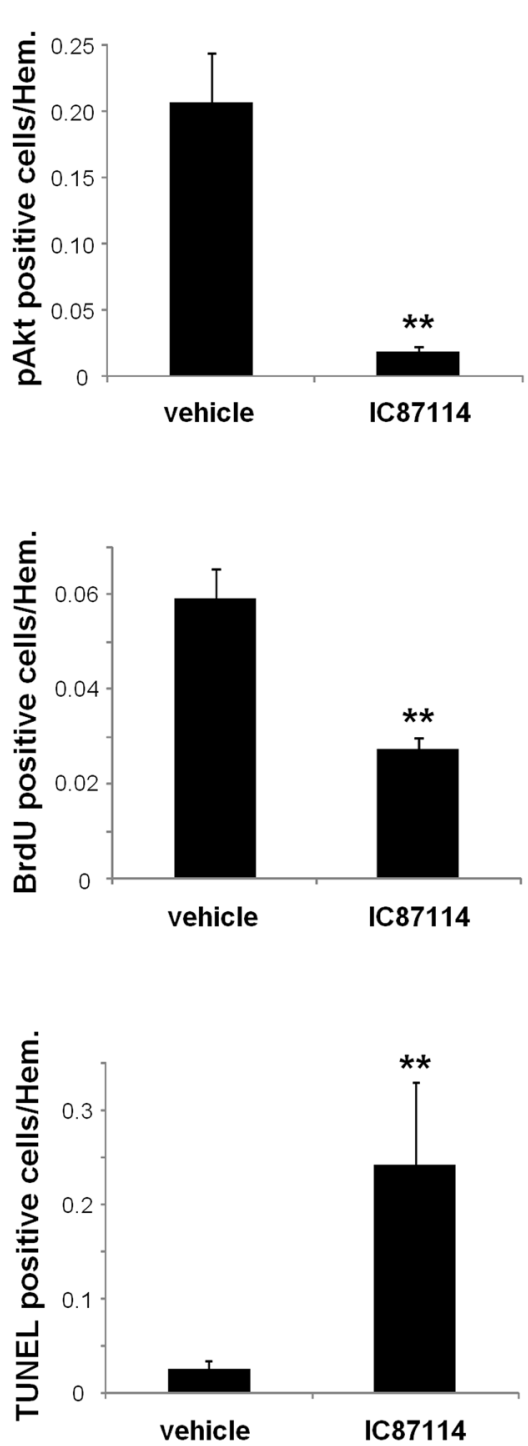

Fig. 4 Efficacy of pharmacological inactivation of the PI3K p1108 against tumour cells. a MDA-MB-231 primary tumours harvested from IC87114 (35 mg/kg)-treated and vehicle-treated BALB/c nude mice were subjected to immunohistochemical analysis using anti p-Akt antibody (brown) and haematoxylin (blue) (left panels). Scale bar $=25 \mu \mathrm{m}$. Comparison of p-Akt-positive cells in tumours of IC87114-treated and vehicletreated mice (right panel). b Cell proliferation in tumours of IC87114-treated and vehicle-treated BALB/C nude mice was determined by BrdU incorporation (brown spots) (left panels). Scale bar $=50 \mu \mathrm{m}$. Comparison of BrdU-positive cells in tumours of IC87114-treated and vehicle-treated mice (right panel). c Apoptosis in tumours of IC87114-treated and vehicle-treated BALB/c nude mice was determined by TUNEL assay (brown spots) (left panels). Scale bar $=50 \mu \mathrm{m}$. Comparison of TUNEL-positive cells in tumours of IC87114-treated and vehicle-treated mice (right panel). All graphs represent means \pm s.e.m. Statistically significant differences are indicated by ${ }^{* *}(P<0.01)$, as determined by the Mann-Whitney test

We then assessed the expression and activity of p110 and PTEN in these tumours. The expression levels of p110 $\delta$ protein gradually increased during tumour growth in mice (Fig. 5c), which is in accordance with that we found in human tumour samples (Fig. 1), whereas the expression levels of $\mathrm{p} 110 \alpha$, used as control, were unaffected (Fig. 5c). In contrast, the activity of PTEN gradually decreased (Fig. 5d, black bars). The expression levels of PTEN protein and the enzymatic activity of $\mathrm{p} 110 \delta$ remained constant during tumour growth (Figs. 5e, f respectively).

We additionally investigated the impact of $\mathrm{p} 110 \delta$ inhibition on PTEN activity in tumour cells. Oral treatment of parallel groups of mice with the p110 $\delta$-selective inhibitor, IC87114, which prevented tumour growth (Fig. 5a), significantly increased PTEN activity in tumour cells (Fig. 5d), indicating that a mechanism by which the p110 inhibition suppresses the survival of tumour cells is via the 


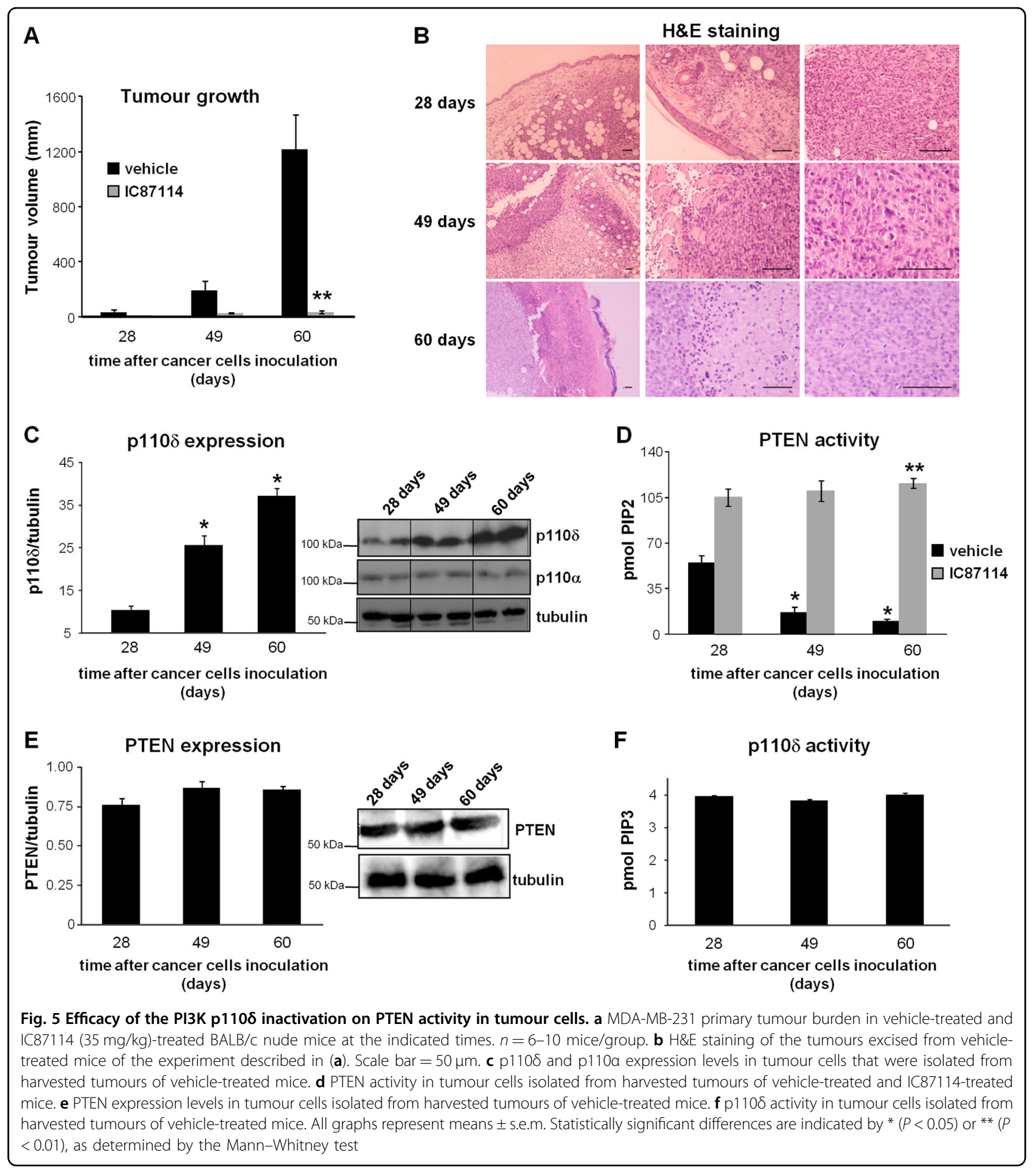

increased PTEN activity. The activity of p110 $\delta$ was determined in the same tumour cells that PTEN activity was evaluated and found to be undetectable confirming the functional effectiveness of the inhibitor (data not shown).
Taken together, these data strongly suggest that the enhanced growth of cancer cells during breast tumour progression is at least in part a result of a gradually reduced activity of PTEN, which correlates with a parallel increase in p110 expression levels. 


\section{Discussion}

Our work shows that the PI3K p110 $\delta$ plays a prominent role in breast cancer progression and that pharmacological inactivation of p110 in mouse experimental models prevents breast tumour growth and metastasis by targeting both cancer cells and macrophages.

The predominant expression of p110 $\delta$ in white blood cells $^{50,51}$ has shifted the interest in the biology of the PI3K p110 $\delta$ pathway toward immune disorders and haematologic cancers ${ }^{52}$; p $110 \delta$-selective inhibitors have been studied in multiple haematologic malignancies ${ }^{25,26}$. The antitumour activity of the initially developed CAL-101 inhibitor (GS-1101 or Idelalisib) ${ }^{26,53}$ is mainly attributed to disruption of the survival and adhesion signals conferred by supporting cells of the B-CLL microenvironment $^{25,52,54,55}$. It is of note that, the targeting of PI3K and its downstream kinases by single-agent inhibitors has limited efficacy with the exception of the PI3K p1108selective inhibitors, which target the tumour stroma and have shown a remarkable clinical activity in CLL ${ }^{52}$.

Our present results clearly show that the effectiveness of the IC87114 p1108-selective inhibitor in preventing breast tumour growth and metastasis is not only a result of its efficacy to inhibit the survival and proliferation of cancer cells but also derives from the modulation of macrophage recruitment to tumour sites. We show that the localization of macrophages in tumour stroma was drastically decreased by IC 87114 treatment, reflecting a similar mechanism with the one observed with the p110 inhibitors in CLL.

The reduced abundance of TAMs in the tumour mass most likely results from an effect of p110 $\delta$ inactivation on survival of TAMs and/or on the recruitment of macrophages to tumour sites. The fact that the localization of macrophages into tumour sites was eliminated in NSG mice that received $\delta^{\mathrm{D} 910 \mathrm{~A} / \mathrm{D} 910 \mathrm{~A}}$ macrophages suggests that $110 \delta$ inactivation mainly affects the recruitment of macrophages to tumour sites. Inactivation of PI3K p110 has been previously shown to block chemotaxis of macrophages $^{49}$ and to affect their polarization ${ }^{56}$ explaining the reduced recruitment of macrophages to tumour environment upon p110 $\delta$ blockade. It is known that the process that macrophages promote the invasion and intravasation of breast cancer cells occurs via association of tumour cells with perivascular TAMs ${ }^{57-61}$. The adoptive transfer of $\delta^{\mathrm{D} 910 \mathrm{~A} / \mathrm{D} 910 \mathrm{~A}}$ macrophages in NSG mice prevented the recruitment of macrophages to tumour environment and suppressed intravasation and metastasis of tumour cells indicating a critical role of PI3K p110 $\delta$ in macrophages in controlling breast cancer metastasis.

It has been recently shown that inhibition of the PI3K p110 $\gamma$ decreases tumour growth by shifting the transcription program in macrophages toward enhanced adaptive immunity, including increased recruitment and cytotoxicity of $\mathrm{T}$ cells ${ }^{62,63}$, but without affecting per se the accumulation of macrophages in tumours ${ }^{62}$. This seems to be a distinct mechanism from the emerging from the present study. In fact, our results clearly show that inactivation of the PI3K p110 $\delta$ significantly reduces the abundance of macrophages in the primary tumour site and almost completely blocks tumour formation in Balb/c nude mice, which lack $\mathrm{T}$ cells. It has also been proposed that inhibition of the PI3K p110 decreases tumour growth by reducing the immune-suppressive function of regulatory $\mathrm{T}$ cells (Tregs) thus enhancing an antitumour cytotoxic T-cell response ${ }^{64}$. The effect of p110 $\delta$ inhibition on the abundance of macrophages to tumour sites that we show here might include the effect of p110 $\delta$ inhibition on Treg function because TAMs are known to mediate their immunoregulatory function through various mechanisms including the CCL22-mediated recruitment of Treg cells $^{65}$. However, the reduced localization of macrophages into tumour sites seems to impact on tumour growth by triggering additional mechanisms since inactivation of p110 $\delta$ blocks tumour growth of p110 $\delta$-expressing tumours even in the absence of $\mathrm{T}$ cells (such as in Balb/ c nude mice (Fig. 2b)). The inactivation of p110 $\delta$ in MDAMB-231-bearing tumour NSG mice (which have defective macrophages and lack $\mathrm{T}$ cells while their tumours express $\mathrm{p} 110 \delta$ ) or in 4T1-bearing tumour Balb/c mice (which have normal macrophages and normal $\mathrm{T}$ cells but their 4T1 tumours do not express p1108) suppresses but is not able to entirely block tumour formation (Figs. 2d, e) pointing at an indispensable role of p $110 \delta$ inactivation in both macrophages and cancer cells for breast tumour growth blockade.

Based on the remarkable clinical impact of the PI3K p1108 inhibitors in blood cancers, especially in some human B-cell malignancies ${ }^{29,66}$, one can postulate that B cells may mediate, at least in part, the effects we observe here. This, however, is not supported by what is known about the role of B cells in solid tumours, with conflicting reports as to whether B-cell presence in solid tumours is a marker of good or bad prognosis ${ }^{67}$. If an association of $B$ cells with good outcomes is the case, then a possible decrease of infiltrating B cells by a p $110 \delta$ inhibitor would conflict with the favourable outcome we present here. On the other hand, a tumour-promoting role of $\mathrm{CD} 20+\mathrm{B}$ cells have been proposed in early breast cancer ${ }^{68}$; however, this does not seem to play a role in the results we show here since tumour growth was prevented by pharmacological blockade of $\mathrm{p} 110 \delta$ even in pre-established tumours (Fig. 2b).

In many cancers, the increased presence of TAMs drives tumour progression and correlates with poor prognosis by promoting cancer cells proliferation, angiogenesis, immunosuppression, invasiveness and metastasis $^{42-44}$. In breast cancer clinical studies, macrophages 
have been found to constitute $50 \%$ of the cell mass and to correlate with poor prognosis in $80 \%$ of the cases ${ }^{58,69,70}$. Furthermore, TAMs are known to influence the response to cancer therapies ${ }^{42,71,72}$. Therefore, a wealth of evidence suggests that combination approaches targeting both cancer cells and TAMs may be clinically beneficial ${ }^{73,74}$. Our findings show that pharmacological inactivation of the PI3K p110 targets both the growth of tumour cells and the recruitment of macrophages to tumour sites leading to a remarkable suppression of breast tumour growth and metastasis.

In recent years, the PIK3CA/PTEN mutational status was considered as a molecular criterion for patient selection. However, accumulating unexplained observations have indicated that this parameter may not be as straightforward as originally hoped for. For example, breast cancer cells were found to be sensitive to growth inhibition by PI3K inhibitors without harbouring mutations in the PTEN or PIK3CA genes ${ }^{37}$; in addition, breast cancer cells with PTEN deficiency were found to be resistant to PI3K inhibitors ${ }^{38}$. Our findings show that although no mutations in $\mathrm{p} 110 \delta$ have been detected thus far in breast cancer, the expression levels of p110 $\delta$ are gradually increased during human breast cancer progression from grade I to grade III indicating that PI3K p110 $\delta$ might play a prominent role in human breast cancer. In support of this, our data show that the gradually increased p $110 \delta$ expression correlates with a gradually reduced PTEN activity, which is recovered and becomes elevated upon treatment with the p110 $\delta$ inhibitor. PTEN is under the negative control of PI3K p110 activity $^{49,75}$ and we have also previously shown that the expression levels of the PI3K p110 $\delta$ in breast cancer cell lines are associated with the activity of WT PTEN ${ }^{40,49}$. Given that PTEN somatic mutations are not very often in human breast cancers ${ }^{39}$, the expression levels of $\mathrm{p} 110 \delta$ may represent a useful straightforward marker, which can predict an effective response of those tumours expressing WT PTEN to therapy with p110 inhibitors.

In conclusion, our data uncover a major role of the PI3K p110 in breast tumour progression and demonstrate that pharmacological inactivation of this isoform prevents tumour growth and metastasis by concomitantly attaching the two major therapeutic targets, named cancer cells and macrophages. Our data support and add to the emerging rationale for targeting PI3K in the tumour stroma and strongly argue in favour of considering the use of $\mathrm{p} 110 \delta$ inhibitors in future clinical trials for breast cancer treatment.

\section{Materials and methods Chemicals}

The PI3K p1108 inhibitor IC87114 was purchased from Chemietek and re-suspended in 30\% PEG-400, 0.5\%
Tween-80 and 5\% propylene glycol for experiments in mice.

\section{Cell culture}

The MDA-MB-231 human breast cancer cell line was a gift from Bart Vanhaesebroeck (Ludwig Institute for Cancer Research, London, United Kingdom). Cells were cultured in Dulbecco's modified Eagle's medium (Invitrogen, Life Technologies) supplemented with $10 \%$ foetal calf serum and $1 \%$ penicillin-streptomycin at $37^{\circ} \mathrm{C}$ with $5 \% \mathrm{CO}_{2}$. Cells were regularly tested for mycoplasma infection. Prior to injection into mice, cells were cultured to $70 \%$ confluence, counted and re-suspended in sterile PBS.

\section{Mice}

All mice were kept in a pathogen-free animal facility at the Institute of Molecular Biology and Biotechnology in Heraklion, Crete. All procedures were approved by the Research Animal Care Committee of Medical School, University of Crete and by the Veterinary Department of Heraklion Prefecture (protocol no. 2182), according to national and EU legislation. Female BALB/c nude mice were obtained from Charles River Laboratories. Female NOD.Cg-Prkdc ${ }^{\text {scid }} I l 2 \mathrm{rg}^{\text {tm1 Wjl }}$ (NOD scid gamma or NSG) mice were obtained from The Jackson Laboratory. $\delta^{\text {D910A/ }}$ D910A mice were kindly provided by Professor Bart Vanhaesebroeck (UCL).

The choice of group sample size was based on calculations using the NC3Rs recommended Resource Equation method, pilot experiments and prior knowledge of the variability of breast tumours in BALB/c nude, NSG and $\mathrm{BALB} / \mathrm{c}$ mice. Mice used in all experiments were female, age-matched (2-3 months of age) and in otherwise excellent physical health. The allocation of animals to experimental groups was performed by simple random sampling at the beginning of each experiment. All mice received injections of tumour cells and then equal number of mice was selected at random for each treatment arm. Each experiment was performed using a minimum of six mice per group (the exact number of mice is indicated in each figure legend) and was repeated at least three times with independent groups of animals to assess reproducibility.

\section{In vivo studies of tumour growth in xenograft and syngeneic models}

Female BALB/c nude or NSG mice were inoculated subcutaneously into the right breast fat pad on day 0 with $10^{6}$ MDA-MB-231 cells in $100 \mu \mathrm{l}$ phosphate-buffered saline (PBS), whereas BALB/c mice were inoculated with 4T1 cells. Mice were then randomly assigned into the control group receiving vehicle alone or into the treatment group receiving $35 \mathrm{mg} / \mathrm{kg} \mathrm{IC} 87114$ by oral gavages 
once daily starting from day 0 or from day +15 . When this is indicated, IC87114 was instead administered by intratumoural injection starting on day +15 when the tumour was palpable. Tumour growth was monitored by measurement of the longest perpendicular tumour diameters using a digital calliper every $3-6$ days. The tumour volume $(\mathrm{V})$ was calculated ${ }^{76}$ as $\mathrm{V}\left(\mathrm{mm}^{3}\right)=$ length $(\mathrm{mm}) \times$ width $(\mathrm{mm})^{2} \times 0.5$. At the end of the study, animals were euthanized and primary tumours and lungs were removed for haematoxylin and eosin (H\&E) staining, immunohistochemistry or determination of PTEN and PI3K p110 activity and expression levels as described below.

\section{Adoptive macrophage transfer, spontaneous and experimental metastasis assay}

WT mice, or mice in which p110 $\delta$ alleles are replaced by a kinase-dead version of p110 $\delta$ (called $\left.\delta^{\mathrm{D} 910 \mathrm{~A} / \mathrm{D} 910 \mathrm{~A}}\right)$, mutated in the ATP binding site ${ }^{45}$, served as macrophage donor mice. WT and $\delta^{\mathrm{D} 910 \mathrm{~A} / \mathrm{D} 910 \mathrm{~A}}$ mice received intraperitoneal injections of $5 \mathrm{ml}$ of 3\% Brewer thioglycollate medium and 1 week later were euthanized and peritoneal macrophages were collected as previously described ${ }^{77}$. MDA-MB-231 cells were inoculated subcutaneously into the right mammary fat pad of recipient NSG mice on day 0 as described above and then randomly assigned into the control group receiving vehicle alone or into the treatment groups receiving macrophages from WT or $\delta^{\mathrm{D} 910 \mathrm{~A} /}$ D910A mice. On day $+15,5 \times 10^{5}$ macrophages from WT or $\delta^{\mathrm{D} 910 \mathrm{~A} / \mathrm{D} 910 \mathrm{~A}}$ mice were intravenously administered into NSG mice. The adoptive macrophage transfer was cycled every $48 \mathrm{~h}$ for 15 days. Tumour growth was monitored by measurement of the tumour diameters using a digital calliper every 5 days and the tumour volume (V) was calculated as described above. At the end of the study, mice were anaesthetised and tumour cell blood burden was determined as described below, followed by sacrifice of the mice and removal of the primary tumour and the lungs for immunohistochemistry as described below. For the experimental lung metastasis assay, $10^{6}$ MDA-MB231 cells were injected into the lateral tail vein of NSG mice, followed 14 days later by intravenous administration of $5 \times 10^{5}$ macrophages from WT or $\delta^{\mathrm{D} 910 \mathrm{~A} / \mathrm{D} 910 \mathrm{~A}}$ mice. The adoptive macrophage transfer was cycled every $48 \mathrm{~h}$ for 15 days. At the end of study, mice were anaesthetised before sacrifice and removal of lungs for immunohistochemistry as described below.

\section{Tumour cell blood burden}

The tumour cell blood burden was measured as previously described ${ }^{46}$. Briefly, mice were anaesthetised and blood was collected from the right atrium by a syringe coated with heparin via heart puncture with a 25 -gauge needle. The blood was plated into culture dishes in which tumour cells were selectively grown by using Geneticin.
Tumour cell clones in the dish were counted and the tumour blood burden was calculated as the number of colonies in the dish divided by the volume of the blood taken.

\section{Immunohistochemistry}

Paraffin-embedded and formalin-fixed tissues from mice were handled as previously described ${ }^{78}$. Briefly, tissue sections were deparaffinized and dehydrated through graded ethanol series. Sections were treated with $3 \%$ hydrogen peroxide for $30 \mathrm{~min}$ at $20^{\circ} \mathrm{C}$ (to inactivate endogenous peroxidase activity) and rinsed in PBS. Epitope unmasking was performed by digestion with $0.2 \%$ trypsin for $10 \mathrm{~min}$ at room temperature (RT) (in the case of anti-pAkt antibody) or by heating for $40 \mathrm{~min}$ in citrate buffer (pH6.0) (in the case of anti-vimentin). The tissue sections were first blocked for nonspecific binding with goat serum (when pAkt antibody was used) or $1 \%$ bovine serum albumin for $1 \mathrm{~h}$ at RT (for the other antibodies) and then incubated with the primary antibodies overnight at 4 ${ }^{\circ} \mathrm{C}$ (1:50 for pAkt (Cell Signalling \#4060), 1/50 for F4/80 (Bio-Rad \#MCA497GA) and 1/200 for vimentin (Thermo Scientific \#RM-9120)). The tissue sections were then incubated with an anti-rat (for F4/80) or an anti-rabbit horseradish peroxidase (for pAkt and vimentin) with $\mathrm{DAB}$ (3,3'-diaminobenzidine) and $\mathrm{H}_{2} \mathrm{O}_{2}$, counterstained with haematoxylin and mounted with Vectashield mounting medium (Vector Labs). The counting of pAkt-positive and F4/80-positive cells was performed using ImageJ software $(\mathrm{NIH})$. Vimentin was quantified as the average pixel intensity per field of view using Scion Image freeware (Scion Corp., Frederick, MD, USA) ${ }^{79}$. Values are presented as means \pm s.e.m of stained cells counted from 5 to 8 fields/section (randomly selected) and from 3 sections/ determination. The immunohistochemisty experiments were performed using tissues from at least three repeat experiments. The results were similar among different experiments. For human cancer tissues, immunohistochemistry was performed on $4 \mu \mathrm{m}$ thick sections of formalin-fixed, paraffin-embedded archival breast cancer tissues of the Pathology Department (University Hospital, Heraklion, Greece). Following deparaffinization and rehydration, the tissue sections where pre-treated by microwaving in EDTA solution ( $\mathrm{pH} 8.0$ ) for $15 \mathrm{~min}$ at 500 W followed by cooling at RT for $20 \mathrm{~min}$. The anti-p110 antibody (Abcam \#ab200372) was incubated for $1 \mathrm{~h}$ at RT. The DAKO REAL EnVision Detection System K5007 was used according to the manufacturer's instructions for visualization with $\mathrm{DAB}$ chromogen. For double staining, the anti-CD68 antibody (Thermo Scientific \#MA5-13324) was subsequently incubated for $1 \mathrm{~h}$ at RT at $1 / 200$ dilution and Envision G2 System was used according to the manufacturer's instructions for visualization with alkaline-phosphatase (Permanent Red). Counterstaining 
was performed using Meyer's haematoxylin. Immunohistochemical results were first evaluated in a semiquantitative manner and scored according to the percentages of positive stained cells $(1+: 5-25 \%$ of cells stained, $2+: 25-50 \%$ of cells stained, $3+: 50-100 \%$ of cells stained). Cytoplasmic and focal staining was considered positive. The $\mathrm{p} 110 \delta$ expression profile was concordant in all cases of each grade analyzed (20 individual cases of grade I, 20 individual cases of grade II and 20 individual cases of grade III).The counting of $\mathrm{p} 110 \delta$-positive cancer cells and the measurement of reciprocal intensity ${ }^{80}$ of the p110 $\delta$ staining were performed using Image J software $(\mathrm{NIH})$. Values are presented as means \pm s.e.m. of the $\%$ of p110 $\delta$-stained cancer cells versus haematoxylin-stained cells or as means \pm s.e.m. of the reciprocal intensity of p110 $\delta$ staining in cancer cells or macrophages of randomly selected 6-12 fields/image and 3 images/patient for all patients.

\section{BrdU incorporation}

Mice were injected intraperitoneally with $100 \mathrm{mg} / \mathrm{kg}$ bodyweight of BrdU (Calbiochem) $2 \mathrm{~h}$ before euthanasia and BrdU-positive tumour cells were detected using a BrdU staining kit (Millipore \#2760) according to the manufacturer's instructions. The counting of BrdUpositive cells was performed using ImageJ software $(\mathrm{NIH})$. Values are presented as means \pm s.e.m. of BrdUpositive/haematoxylin-stained cells counted from 5 to 8 fields/section (randomly selected) and 3 sections/measurement. The BrdU incorporation procedure was performed on tissues obtained from at least three separate experimental groups of animals for each treatment condition. The results were similar among the different experimental repeats.

\section{TUNEL assay}

The detection of apoptosis was performed using the DeadEnd colorimetric TUNEL system (Promega \#G7130), according to the manufacturer's instructions. The counting of TUNEL-positive cells was performed using ImageJ software $(\mathrm{NIH})$. Values are presented as means $\pm \mathrm{s}$. e.m. of TUNEL-positive/haematoxylin-stained cells counted from 5 to 8 fields/section (randomly selected) and 3 sections/measurement. The TUNEL procedure was performed on tissues obtained from at least three separate experimental groups of animals for each treatment condition. The results were similar among different experiments.

\section{Immunoprecipitation (IP) and Western blot (WB)}

Cells were isolated from tumours using an enzyme mixture consisting of $0.05 \mathrm{mg} / \mathrm{mL}$ Collagenase I, $0.05 \mathrm{mg} /$ $\mathrm{mL}$ Collagenase IV and $0.01 \mathrm{mg} / \mathrm{mL}$ DNase I in HBSS (Hank's Balanced Salt Solution) followed by isolation of cancer cells using the Tumor Cell Isolation kit (Cell Biolabs). Cells were lysed in lysis buffer containing $150 \mathrm{mM} \mathrm{NaCl}, 1,5 \mathrm{mM} \mathrm{MgCl}_{2}, 1 \mathrm{mM}$ EGTA, 10\% glycerol, $100 \mathrm{mM}$ NaF, $25 \mathrm{mM}$ glycerolphosphate, 1\% IPEGAL (octylphenoxypolyethoxyethanol), $1 \mathrm{mM}$ DTT (dithiothreitol), $10 \mathrm{mM}$ Na-pyrophosphate, $1 \mathrm{mM}$ PMSF (phenylmethylsulfonyl fluoride), $10 \mu \mathrm{g} / \mathrm{ml}$ aprotinin, $10 \mathrm{mM} \mathrm{Na}_{4} \mathrm{VO}_{3}$ and $50 \mathrm{mM}$ Hepes, $\mathrm{pH}$ 7.4 (in the case of the PTEN lipid phosphatase activity assay) or in lysis buffer containing $20 \mathrm{mM}$ Tris- $\mathrm{HCl}, \mathrm{pH}$ 7.4, $137 \mathrm{mM} \mathrm{NaCl}$, $1 \mathrm{mM} \mathrm{CaCl}_{2}, 1 \mathrm{mM} \mathrm{MgCl}_{2}, 1 \mathrm{mM}$ sodium orthovanadate, $1 \% \mathrm{NP}-40$ and $1 \mathrm{mM}$ PMSF (in the case of the p1108 activity assay), followed by clearing of the lysates by centrifugation in a cooled microcentrifuge. Supernatants were directly immunoprecipitated at $4{ }^{\circ} \mathrm{C}$ overnight using an anti-PTEN (Santa Cruz Biotechnology \#A2B1 or \#sc-6818)

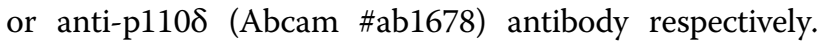
Immune complexes were collected with $50 \%$ slurry of protein A-Sepharose after incubation for $2-3 \mathrm{~h}$ at $4^{\circ}$ and washed according to the manufacturer's instructions (Echelon Biosciences) provided the ELISA kits. For analysis of total cell lysates by western blotting, $50-70 \mu \mathrm{g}$ of cell extract (of the same samples used for the activity assay) was loaded per lane on an sodium dodecyl sulphate-polyacrylamide gel electrophoresis gel and transferred onto PVDF (Polyvinylidene Difluoride) membranes. The blots were probed with the indicated antibodies (anti-PTEN (Santa Cruz Biotechnology \#sc-9145) or anti-p1108 (Santa Cruz Biotechnology \#sc-7176)), followed by detection using enhanced chemiluminescence (GE Healthcare).

\section{PTEN lipid phosphatase activity assay}

PTEN was immunoprecipitated from cell lysates derived from tumour cells isolated from each tumour-bearing mouse from each experimental group and its lipid phosphatase activity measured by ELISA (Enzyme-linked Immunosorbent Assay), according to the manufacturer's instructions (Echelon Biosciences). The PI(4,5)P2 produced was determined by comparison with a standard curve consisting of $\mathrm{PI}(4,5) \mathrm{P} 2$ standards bound to the ELISA plate. Different amounts of proteins of cell lysates, from which PTEN was immunoprecipitated, were tested in pilot experiments to ensure that the appropriate amount of enzyme were used so that the produced PI $(4,5)$ P2 was in the range of the respective standard curve.

\section{PI3K p1108 lipid kinase activity assay}

p110 $\delta$ was immunoprecipitated from cell lysates derived from tumour cells isolated from each tumour-bearing mouse from each experimental group and its lipid kinase activity measured by ELISA, according to the manufacturer's (Echelon Biosciences) instructions. The PI $(3,4,5)$ P3 produced was determined by comparison with a 
standard curve consisting of $\mathrm{PI}(3,4,5) \mathrm{P} 3$ standards bound to the ELISA plate. Different amounts of proteins of cell lysates, from which $\mathrm{p} 110 \delta$ was immunoprecipitated, were tested in pilot experiments to ensure that the appropriate amount of enzyme were used so that the produced PI $(3,4,5) \mathrm{P} 3$ was in the range of the respective standard curve.

\section{Statistical analysis}

Error bars displayed in the figure section represent s.e.m. and were calculated from technical or biological replicates as described in the figure legends and in the description of the respective methods. Data shown are representative of at least three independent experiments, including animal studies, histological images, blots and gels. Data were analyzed using the STATISTICA 7 statistical software package. Statistical significance was determined using the non-parametric Mann-Whitney test; " $P$ $<0.05$; ${ }^{* *} P<0.01 ;{ }^{* * *} P<0.001$.

\section{Acknowledgements}

We thank Professor Sifis Papamatheakis (Institute of Molecular Biology and Biotechnology) for help with NSG mice and Ms Deppie Tsoukatou (Institute of Molecular Biology and Biotechnology) for technical assistance. We are also grateful to Professor Bart Vanhaesebroeck (UCL) for $\delta^{\mathrm{D} 910 \mathrm{~A} / \mathrm{D} 910 \mathrm{~A}}$ mice and to Professor Stavros Topouzis for his critical reading of the manuscript. This research was supported by the programme NSRF 2007-2013, "Education \& Lifelong Learning" (Action ARISTEIA II, Project No. 4078) of the Ministry of Education and Religious Affairs, Greece, co-financed by Greece and the European Union and partially supported by the Research Committee of the University of Crete (KA 4720) (E.A.P.).

\section{Author details \\ 'Department of Biochemistry, School of Medicine, University of Crete, Heraklion, Greece. ${ }^{2}$ Department of Pathology, University Hospital, School of Medicine, University of Crete, Heraklion, Greece. ${ }^{3}$ Department of Surgical Oncology, University Hospital, School of Medicine, University of Crete, Heraklion, Greece. ${ }^{4}$ Department of Obstetrics and Gynaecology, University Hospital, School of Medicine, University of Crete, Heraklion, Greece}

\section{Authors' contributions}

E.G. and M.B.-B. performed experiments with mice and data analyses and drafted the manuscript. M.A. performed experiments with mice. N.T. performed immunohistochemistry experiments. M.T. performed histology and performed and interpreted histopathology and immunohistochemistry of human samples. Clinical samples and clinical information was obtained from E.dB. E.T. performed immunohistochemistry experiments on human samples. A.M. supervised experiments. E.A.P conceived the project, designed and analysed the experiments, supervised experiments and wrote the paper.

\section{Conflict of interest}

The authors declare that they have no conflict of interest.

\section{Publisher's note}

Springer Nature remains neutral with regard to jurisdictional claims in published maps and institutional affiliations.

Supplementary Information accompanies this paper at https://doi.org/ 10.1038/s41419-018-0717-4.

Received: 14 December 2017 Revised: 1 April 2018 Accepted: 20 April 2018 Published online: 07 June 2018

\section{References}

1. Vanhaesebroeck, B., Leevers, S. J., Panayotou, G. \& Waterfield, M. D. Phosphoinositide 3-kinases: a conserved family of signal transducers. Trends Biochem. Sci. 22, 267-272 (1997).

2. Vanhaesebroeck, B., Guillermet-Guibert, J., Graupera, M. \& Bilanges, B. The emerging mechanisms of isoform-specific PI3K signalling. Nat. Rev. Mol. Cell Biol. 11, 329-341 (2010).

3. Vanhaesebroeck, B., Whitehead, M. A. \& Pineiro, R. Molecules in medicine minireview: isoforms of PI3K in biology and disease. J. Mol. Med (Berl.) 94, 5-11 (2016).

4. Chang, H. W. et al. Transformation of chicken cells by the gene encoding the catalytic subunit of PI 3-kinase. Science 276, 1848-1850 (1997).

5. Duff, R. G. \& Vogt, P. K. Characteristics of two new avian tumor virus subgroups. Virology 39, 18-30 (1969).

6. Samuels, Y. \& Velculescu, V. E. Oncogenic mutations of PIK3CA in human cancers. Cell Cycle 3, 1221-1224 (2004).

7. Samuels, Y. et al. High frequency of mutations of the PIK3CA gene in human cancers. Science 304, 554 (2004).

8. Jackson, S. P. et al. PI 3-kinase p110b: a new target for antithrombotic therapy. Nat. Med. 11, 507 (2005)

9. Jia, S. et al. Essential roles of PI(3)K-p110 in cell growth, metabolism and tumorigenesis. Nature 454, 776-779 (2008).

10. Ciraolo, E. et al. Phosphoinositide 3-kinase p110beta activity: key role in metabolism and mammary gland cancer but not development. Sci. Signal. 1, ra3 (2008).

11. Zhu, Q. et al. Phosphoinositide 3-OH kinase p85alpha and p110beta are essential for androgen receptor transactivation and tumor progression in prostate cancers. Oncogene 27, 4569-4579 (2008).

12. Torbett, N. E. et al. A chemical screen in diverse breast cancer cell lines reveals genetic enhancers and suppressors of sensitivity to PI3K isoform-selective inhibition. Biochem. J. 415, 97-110 (2008).

13. Wee, S. et al. PTEN-deficient cancers depend on PIK3CB. Proc. Natl. Acad. Sci. USA 105, 13057-13062 (2008).

14. Parsons, D. W. et al. An integrated genomic analysis of human glioblastoma multiforme. Science 321, 1807-1812 (2008).

15. TGCA. Comprehensive genomic characterization defines human glioblastoma genes and core pathways. Nature 455, 1061-1068 (2008).

16. Thomas, R. K. et al. High-throughput oncogene mutation profiling in human cancer. Nat. Genet. 39, 347-351 (2007).

17. Wood, L. D. et al. The genomic landscapes of human breast and colorectal cancers. Science 318, 1108-1113 (2007).

18. Angulo, I. et al. Phosphoinositide 3-kinase delta gene mutation predisposes to respiratory infection and airway damage. Science 342, 866-871 (2013).

19. Lucas, C. L. et al. Dominant-activating germline mutations in the gene encoding the PI(3)K catalytic subunit p110delta result in T-cell senescence and human immunodeficiency. Nat. Immunol. 15, 88-97 (2014).

20. Coulter, T. I. et al. Clinical spectrum and features of activated phosphoinositide 3-kinase delta syndrome: a large patient cohort study. J. Allergy Clin. Immunol. 139, 597-606 e594 (2017).

21. Zhang, J. et al. Genetic heterogeneity of diffuse large B-cell lymphoma. Proc. Natl. Acad. Sci. USA 110, 1398-1403 (2013).

22. Rommel, C., Camps, M. \& Ji, H. PI3K[delta] and PI3K[gamma]: partners in crime in inflammation in rheumatoid arthritis and beyond? Nat. Rev. Immunol. 7, 191-201 (2007).

23. Rommel, C. Taking PI3KS and PI3KY one step ahead: dual active PI3K $/ Y$ inhibitors for the treatment of immune-mediated inflammatory diseases. Curr. Top. Microbiol. Immunol. 346, 279-299 (2010).

24. Soond, D. R. et al. PI3K p110delta regulates T-cell cytokine production during primary and secondary immune responses in mice and humans. Blood 115, 2203-2213 (2010)

25. Castillo, J. J., Furman, M. \& Winer, E. S. CAL-101: a phosphatidylinositol-3-kinase p110-delta inhibitor for the treatment of lymphoid malignancies. Expert. Opin. Investig. Drugs 21, 15-22 (2012).

26. Fruman, D. A. \& Rommel, C. PI3K $\delta$ inhibitors in cancer: rationale and serendipity merge in the clinic. Cancer Discov. 1, 562-572 (2011).

27. Furman, R. R. et al. Idelalisib and rituximab in relapsed chronic lymphocytic leukemia. N Engl. J. Med. 370, 997-1007 (2014).

28. Gopal, A. K. et al. PI3K $\delta$ inhibition by Idelalisib in patients with relapsed indolent lymphoma. New Engl. J. Med. 370, 1008-1018 (2014).

29. Tzenaki, N. \& Papakonstanti, E. A. p110d PI3 kinase pathway: emerging roles in cancer. Front Oncol. 3: 40, 1-16 (2013). 
30. Raedler, L. A. Zydelig (Idelalisib): first-in-class PI3 kinase inhibitor approved for the treatment of 3 hematologic malignancies. Am. Health Drug Benefits $\mathbf{8}$ (Spec Feature), 157-162 (2015).

31. Campbell, I. G. et al. Mutation of the PIK3CA gene in ovarian and breast cancer. Cancer Res. 64, 7678-7681 (2004).

32. Vivanco, I. \& Sawyers, C. L. The phosphatidylinositol 3-kinase-Akt pathway in human cancer. Nat. Rev. Cancer 2, 489-501 (2002).

33. Engelman, J. A., Luo, J. \& Cantley, L. C. The evolution of phosphatidylinositol 3kinases as regulators of growth and metabolism. Nat. Rev. Genet. 7, 606-619 (2006).

34. Yuan, T. L. \& Cantley, L. C. PI3K pathway alterations in cancer: variations on a theme. Oncogene 27, 5497-5510 (2008).

35. Bermudez-Brito, M., Goulielmaki, E. \& Papakonstanti, E. A. Focus on PTEN regulation. Front. Oncol. 5, 166 (2015).

36. Edgar, K. A. et al. Isoform-specific phosphoinositide 3-kinase inhibitors exert distinct effects in solid tumors. Cancer Res. 70, 1164-1172 (2010).

37. O'Brien, C. et al. Predictive biomarkers of sensitivity to the phosphatidylinositol 3 kinase inhibitor GDC-0941 in breast cancer preclinical models. Clin. Cancer Res. 16, 3670-3683 (2010).

38. Tanaka, H. et al. The selective class I PI3K inhibitor CH5132799 targets human cancers harboring oncogenic PIK3CA mutations. Clin. Cancer Res. 17, 3272-3281 (2011).

39. Chalhoub, N. \& Baker, S. J. PTEN and the PI3-kinase pathway in cancer. Annu. Rev. Pathol. 4, 127-150 (2009).

40. Tzenaki, N. et al. High levels of p110d PI3K expression in solid tumor cells suppresses PTEN activity, generating cellular sensitivity to p110d inhibitors through PTEN activation. FASEB J. 26, 2498-2508 (2012).

41. Sadhu, C., Masinovsky, B., Dick, K., Sowell, C. G. \& Staunton, D. E. Essential role of phosphoinositide 3-kinase d in neutrophil directional movement. J. Immunol. 170, 2647-2654 (2003).

42. Ostuni, R., Kratochvill, F., Murray, P. J. \& Natoli, G. Macrophages and cancer: from mechanisms to therapeutic implications. Trends Immunol. 36, 229-239 (2015).

43. Qian, B. \& Pollard, J. Macrophage diversity enhances tumor progression and metastasis. Cell 141, 39-51 (2010).

44. Kitamura, T., Qian, B.-Z. \& Pollard, J. W. Immune cell promotion of metastasis. Nat. Rev. Immunol. 15, 73-86 (2015).

45. Okkenhaug, $\mathrm{K}$. et al. Impaired $\mathrm{B}$ and $\mathrm{T}$ cell antigen receptor signaling in $\mathrm{p} 110 \mathrm{~d}$ PI 3-kinase mutant mice. Science 297, 1031-1034 (2002).

46. Xue, C. et al. Epidermal growth factor receptor overexpression results in increased tumor cell motility in vivo coordinately with enhanced intravasation and metastasis. Cancer Res. 66, 192-197 (2006).

47. Gilles, C. et al. Transactivation of vimentin by $\beta$-catenin in human breast cancer cells. Cancer Res. 63, 2658-2664 (2003).

48. Korsching, E. et al. The origin of vimentin expression in invasive breast cancer: epithelial-mesenchymal transition, myoepithelial histogenesis or histogenesis from progenitor cells with bilinear differentiation potential? J. Pathol. 206, 451-457 (2005).

49. Papakonstanti, E. A., Ridley, A. J. \& Vanhaesebroeck, B. The p110delta isoform of PI 3-kinase negatively controls RhoA and PTEN. EMBO J. 26, 3050-3061 (2007)

50. Vanhaesebroeck, B. et al. p110delta, a novel phosphoinositide 3-kinase in leukocytes. Proc. Natl. Acad. Sci. USA 94, 4330-4335 (1997).

51. Chantry, D. et al. p110delta, a novel phosphatidylinositol 3-kinase catalytic subunit that associates with p85 and is expressed predominantly in leukocytes. J. Biol. Chem. 272, 19236-19241 (1997).

52. Fruman, D. A. \& Rommel, C. PI3K and cancer: lessons, challenges and opportunities. Nat. Rev. Drug. Discov. 13, 140-156 (2014).

53. Lannutti, B. J. et al. CAL-101, a p110delta selective phosphatidylinositol-3kinase inhibitor for the treatment of B-cell malignancies, inhibits PI3K signaling and cellular viability. Blood 117, 591-594 (2011).

54. Herman, S. E. M. et al. Phosphatidylinositol 3-kinase-delta inhibitor CAL-101 shows promising preclinical activity in chronic lymphocytic leukemia by antagonizing intrinsic and extrinsic cellular survival signals. Blood 116, 2078-2088 (2010).

55. Hoellenriegel, J. et al. The phosphoinositide 3'-kinase delta inhibitor, CAL-101, inhibits B-cell receptor signaling and chemokine networks in chronic lymphocytic leukemia. Blood 118, 3603-3612 (2011).
56. Weisser, S. B. et al. Arginase activity in alternatively activated macrophages protects PI3Kp110 deficient mice from dextran sodium sulfate induced intestinal inflammation. Eur. J. Immunol. 44, 3353-3367 (2014).

57. Wang, W. et al. Tumor cells caught in the act of invading: their strategy for enhanced cell motility. Trends Cell Biol. 15, 138-145 (2005).

58. Condeelis, J. \& Pollard, J. W. Macrophages: obligate partners for tumor cell migration, invasion, and metastasis. Cell 124, 263-266 (2006).

59. Goswami, S. et al. Macrophages promote the invasion of breast carcinoma cells via a colony-stimulating factor-1/epidermal growth factor paracrine loop. Cancer Res. 65, 5278-5283 (2005).

60. Wyckoff, J. et al. A paracrine loop between tumor cells and macrophages is required for tumor cell migration in mammary tumors. Cancer Res. 64 7022-7029 (2004)

61. Wyckoff, J. B. et al. Direct visualization of macrophage-assisted tumor cell intravasation in mammary tumors. Cancer Res. 67, 2649-2656 (2007).

62. Kaneda, M. M. et al. PI3Kgamma is a molecular switch that controls immune suppression. Nature 539, 437-442 (2016).

63. Kaneda, M. M. et al. Macrophage PI3Kgamma drives pancreatic ductal adenocarcinoma progression. Cancer Discov. 6, 870-885 (2016).

64. Ali, K. et al. Inactivation of PI(3)K p110delta breaks regulatory T-cell-mediated immune tolerance to cancer. Nature 510, 407-411 (2014).

65. Curiel, T. J. et al. Specific recruitment of regulatory T cells in ovarian carcinoma fosters immune privilege and predicts reduced survival. Nat. Med. 10, 942-949 (2004).

66. Vanhaesebroeck, B. \& Khwaja, A. PI3Kdelta inhibition hits a sensitive spot in B cell malignancies. Cancer Cell. 25, 269-271 (2014).

67. Flynn, N. J., Somasundaram, R., Arnold, K. M. \& Sims-Mourtada, J. The multifaceted roles of $B$ cells in solid tumors: emerging treatment opportunities. Target Oncol. 12, 139-152 (2017).

68. Mahmoud, S. M. et al. The prognostic significance of B lymphocytes in invasive carcinoma of the breast. Breast Cancer Res. Treat. 132, 545-553 (2012).

69. Bingle, L., Brown, N. J. \& Lewis, C. E. The role of tumour-associated macrophages in tumour progression: implications for new anticancer therapies. J. Pathol. 196, 254-265 (2002).

70. Lewis, C. E., Leek, R., Harris, A. \& McGee, J. O. Cytokine regulation of angiogenesis in breast cancer: the role of tumor-associated macrophages. J. Leukoc. Biol. 57, 747-751 (1995).

71. Mantovani, A. \& Allavena, P. The interaction of anticancer therapies with tumor-associated macrophages. J. Exp. Med. 212, 435-445 (2015).

72. De Palma, M. \& Lewis, C. E. Cancer: macrophages limit chemotherapy. Nature 472, 303-304 (2011).

73. Germano, G. et al. Role of macrophage targeting in the antitumor activity of trabectedin. Cancer Cell. 23, 249-262 (2013).

74. Ries Carola, $\mathrm{H}$. et al. Targeting tumor-associated macrophages with anti-CSF$1 \mathrm{R}$ antibody reveals a strategy for cancer therapy. Cancer Cell. 25, 846-859 (2014).

75. Tzenaki, N., Aivaliotis, M. \& Papakonstanti, E. A. Focal adhesion kinase phosphorylates the phosphatase and tensin homolog deleted on chromosome 10 under the control of p110delta phosphoinositide-3 kinase. FASEB J. 29, 4840-4852 (2015).

76. Anzai, K. et al. Effectiveness of combined treatment using X-rays and a phosphoinositide 3-kinase inhibitor, ZSTK474, on proliferation of HeLa cells in vitro and in vivo. Cancer Sci. 102, 1176-1180 (2011).

77. Xiong, W. et al. Membrane-type 1 matrix metalloproteinase regulates macrophage-dependent elastolytic activity and aneurysm formation in vivo. J. Biol. Chem. 284, 1765-1771 (2009).

78. Robertson, D., Savage, K., Reis-Filho, J. \& Isacke, C. Multiple immunofluorescence labelling of formalin-fixed paraffin-embedded (FFPE) tissue. Bmc. Cell. Biol. 9, 13 (2008).

79. Prasad, K. \& Prabhu, G. K. Image analysis tools for evaluation of microscopic views of immunohistochemically stained specimen in medical research-a review. J. Med. Syst. 36, 2621-2631 (2012).

80. Nguyen, D. Quantifying chromogen intensity in immunohistochemistry via reciprocal intensity. Protocol Exchange-Nature (2013) https://doi.org/10.1038/ protex.2013.097. 